\title{
Enunciación
}

http://revistas.udistrital.edu.co/ojs/index.php/enunc

DOI: http://dx.doi.org/10.14483/udistrital.jour.enunc.2016.1.a01

enunciación

Artículo de inVestigación

\section{Constitución de sujeto maestro en prácticas de resistencia en Colombia}

\section{Teacher subject constitution in resistance practices in Colombia}

\author{
Pilar Méndez Rivera ${ }^{1}$
}

Para citar este artículo: Méndez, P. (2016). Constitución de sujeto maestro en prácticas de resistencia en Colombia. Enunciación, 21(1), 15-30.

Recibido: 29-enero-2016 /Aprobado: 25-abril-2016

\section{Resumen}

Este artículo comparte los resultados de una investigación que analizó la constitución de sujeto maestro en las prácticas de resistencia en Colombia en el periodo comprendido entre 1930 y 2013 para dar cuenta de los cambios en sus prácticas frente al reclamo de un estatus profesional de la docencia. Se identifican y describen los modos como las prácticas de resistencia han contribuido a la constitución de sujeto maestro en Colombia, con el propósito de situar la participación del movimiento magisterial en las distintas formas que han definido o connotado la condición de maestro en Colombia. En cuanto estudio arqueológico (Foucault, 1969), la mirada al pasado para comprender el presente permitió entender los modos en que la forma maestro ha sido intervenida por distintas fuerzas. El archivo de la resistencia que se construyó en esta investigación organizó temáticamente enunciados provenientes de distintas fuentes documentales (revistas sindicales, revistas académicas, prensa, leyes, decretos, etc.) y los sometió a los procesos de eventualización, líneas de fuerza, condiciones de posibilidad, desmultiplicación causal, polimorfismo creciente y puntos en suspenso. Los resultados de esta investigación identifican tres trayectos importantes de las prácticas de resistencia y del sujeto que se constituye en ellas: el primero ligado a la lucha gremial reivindicativa, el segundo referido a las luchas de sí y un tercer trayecto de disputas por la distinción de sí mismo en la función docente.

Palabras clave: sujeto, maestro, resistencia, lucha, discurso, poder.

\begin{abstract}
This article shares the results of a research work focused on the constitution of teacher subject in resistance practices in Colombia during the period 1930 and 2013 to show the changes in the teachers' claim practices of a teaching professionalization Book. It identifies and describes the ways how the practices of resistance have contributed to the constitution of teacher subject in Colombia for the purpose of placing the participation of teachers' movements in the various forms that have been defined or connoting their teacher status. As an archaeological study, look to the past to understand the present allowed to comprehend the ways in which the teacher form has been taken over by various forces. The resistance file, built in this research, organized statements thematically from various documentary sources
\end{abstract}

1 Profesora asociada Universidad Distrital Francisco José de Caldas, Doctora en Educación y directora del grupo de investigación Intertexto. Correo electrónico: pmendez@udistrital.edu.co 
(teachers' labor union magazines, journals, newspapers, laws, decrees, etc.) and subjected to the processes of casualization, lines of force, conditions of possibility, causal multiplication, growing polymorphism and suspended points.

The results of this research reveal three important paths in the practices of resistance and of the subject that is in them. The first linked to the

\section{INTRODUCCIÓN}

La búsqueda de comprensión con lo que sucede hoy con las luchas y las prácticas de resistencia de los maestros en Colombia es una tarea compleja y problemática. Aun en los discursos actuales del magisterio sindicalizado se advierte un inconformismo, un malestar frente a la desunión, la falta de solidaridad y la pasividad de los docentes en torno a las luchas que deberían librarse por un nuevo estatuto de profesionalización de la docencia. De hecho, puede colegirse la sensación de una pérdida que reclama la fuerza y el carácter de las luchas de ayer. Pareciera que algo anda mal con la resistencia: las viejas formas de lucha e incluso la misma sindicalización, proclamadas como vencedoras en determinados periodos de tiempo, que ya no movilizan a los docentes. ¿Será acaso que el docente ya no lucha? O, quizás, ¿que las prácticas de resistencia de hoy no son las mismas de ayer? ¿Qué ha pasado con el maestro y su resistencia? ¿Se puede decir que se ha operado un cambio de la resistencia del maestro a la actual resistencia del docente?

No hay duda de que cualquier intento por comprender quién es el maestro contemporáneo no puede eludir el papel de su resistencia y lucha en el estado actual de su condición. No obstante, habría que precisar que la resistencia como práctica es un acontecimiento histórico difícil de capturar y retratar. Historiar dichas prácticas remite insoslayablemente al análisis de distintas líneas de fuerza (gremiales, económicas, políticas, sociales y jurídicas) que revelan relaciones protest union struggle, the second referred to the struggles of themselves and the third one by distinguishing himself from the teaching defined as function.

Keywords: Subject, teacher, resistance, struggle, discourse, power.

complejas en un juego combinado de poder/saber, donde solicitudes y respuestas son sometidas al azar de sus transformaciones.

En muchos de los trabajos sobre los maestros y sus luchas en América Latina (Street, 1998a, 1998b, 1997; Tiramonti, 2001; Tenti, 2005, 2006), los procesos que se destacan aparecen mezclados con exigencias de tipo económico y político, revelando la colonización de otros discursos en la educación, pero sobre todo, predeterminando quién debe ser el maestro. Ante este escenario, la resistencia como práctica de libertad $^{2}$ (Fornet-Betancourt, Becker y Gómez-Muller, 1984; Sábato, 2000; Giroux, 2003) ha desempeñado un papel importante que le ha permitido al maestro, en ese juego de exigencias y respuestas, oponerse a formas que lo predeterminan $y$, a su vez, reclamar la mejora de sus condiciones de trabajo en procura de un estatuto de profesión de la docencia. Sin embargo, la resistencia como práctica no obedece a un proceso lineal, evolutivo, dado, exento en sí mismo de conflicto; ella misma se transforma para insertarse en nuevas tácticas y estrategias de lucha. Aquí operan distintas fuerzas, donde el maestro es también una fuerza que afecta y es afectada por otras. En este trabajo se analizaron las luchas y las transformaciones de

2 Para explicar el concepto de gubernamentalidad, Fornet-Betancourt, Becker y Gómez-Muller (1984) precisa que los individuos en su libertad pueden establecer un conjunto de prácticas a través de las cuales pueden constituir, instrumentalizar, organizar estrategias en relación con los otros. Lo que pone de relieve la resistencia como una práctica organizada, planeada para hacerle frente al poder como dominación. 
la resistencia de los maestros para acceder a sus transformaciones y a los procesos de subjetividad que configuran las relaciones consigo mismos, y su articulación y relaciones con los otros actores (Estado, escuela, sindicato, estudiante, padre de familia, sociedad).

En esta investigación se propone un giro para rastrear las luchas de los maestros e identificar las fuerzas que direccionan su resistencia; en lugar de abordarlas como conflicto entre Estado y gobierno, las ubica en un escenario que reconoce la resistencia como una relación de poder (Foucault, 2000) atravesada por muchas otras relaciones de fuerza. Para ello, el archivo de la resistencia magisterial que se construyó en este trabajo desde la opción teórica y metodológica de la arqueología, organizó y tematizó los enunciados maestro, poder y lucha en clave con otros enunciados, como, Estado, sociedad y ley, dispersos en distintas fuentes documentales (revistas sindicales, revistas académicas, prensa, leyes, decretos, etc.). Este análisis sirvió para mostrar las estrategias y tácticas de lucha de los maestros y la emergencia de unos enunciados (su preferencia sobre otros, su coexistencia, su abandono), la institucionalización de un saber sobre la docencia, las relaciones de fuerza (activas y pasivas) en la lucha por el dominio o gobierno de sí mismo. En esta línea de descripción, se da cuenta de la transformación de sus luchas, de resistencias verticales a resistencias más horizontales que condujeron a preguntarse por el trabajo de sí, es decir a prácticas de afirmación de su identidad, pero también de los supuestos subsumidos en los discursos que han tocado al maestro en Colombia para dar cuenta de las transformaciones que ha sufrido históricamente el sujeto maestro en Colombia y del papel de la resistencia en dicho proceso.

A partir delo anterior, el problema se formuló de la siguiente manera: la forma maestro ha sido configurada por distintas fuerzas (Estado, sociedad, política, economía) que buscan prescribir quién debe ser el maestro, cómo debe enseñar. Es decir, se exige que el maestro se adapte a formas de ser y actuar, constituyendo prácticas de subjetivación y normalización que ameritan ser visibilizadas. En este escenario, el maestro resiste y también define su subjetividad, se afirma o rechaza y lucha por defender unas condiciones particulares de existencia donde cabe analizar ¿qué papel ha cumplido la resistencia en las luchas de los maestros y en el estado actual de su condición? Por tanto, se planteó como objetivo general: analizar y describir los modos en que las prácticas de resistencia magisterial han contribuido a la constitución del sujeto maestro en Colombia entre 1930 y 2013 para entender las transformaciones que hicieron posibles nuevos enfoques y conceptos en la condición de maestro en Colombia. La investigación da cuenta de cómo formas y prácticas de resistencia han colocado al maestro en una condición social que constituye una manera de pensarse a sí mismo. El análisis no se centra en el poder como dominación, sino que lo entiende como una relación que permite identificar fuerzas de poder/saber que le exigen al maestro desde discursos del deber ser a adaptarse a formas de educador ya prescritas, que le dicen cómo tiene que ser, cómo debe enseñar, cómo debe evaluar constituyendo así prácticas de normalización y subjetivación que ameritan ser visibilizadas.

Desde esta perspectiva analítica, uno de los objetivos específicos de la investigación fue identificar y analizar las formas de constitución de sujeto en las luchas por el estatuto de profesionalización de la docencia en las últimas décadas en Colombia, con el fin de rastrear las regulaciones estatales y su contrapunto con los reclamos de los maestros acerca de su oficio e identidad. Se trata de entender cómo la profesionalización de la docencia fue introducida en los discursos de resistencia, y analizar qué diferencias mantiene con la profesionalización que los discursos oficiales sostienen a través de la vía de los estatutos docentes. 


\section{MARCO TEÓRICO}

\section{La pregunta por la constitución de sujeto en las relaciones poder/resistencia}

La pregunta por la constitución de sujeto maestro en las prácticas de resistencia, conmina el análisis de los distintos campos de actuación en el que sujeto participa, se declara, se autorreconoce y lucha por ser identificado como sujeto. Su participación en la vida pública, en estrecha relación con otros sujetos, lo obliga a posicionarse en la compleja red de relaciones de poder que se tejen alrededor de la confluencia de los campos político, educativo y social, no solo para constituirse como tal, sino también para resistir las formas instauradas por otros sujetos, en especial los que detentan el poder institucionalizado para sujetarlo y regularlo. No obstante, tal como lo afirma Foucault (2007, pp. 54-55), "hay que construir una analítica de poder que ya no tome al derecho como modelo y como código para caracterizar las relaciones entre poder y resistencia" y se adentre en el análisis de la situación estratégica compleja instaurada por un sujeto que lucha por liberarse de fuerzas que lo constriñen, pero a su vez, atravesado por esta, se piensa a sí mismo ${ }^{3}$.

Las prácticas de resistencia se validan como escenario para analizar las formas en que los propios maestros luchan por unas condiciones de posibilidad, al tiempo que afectan y son afectados por otras relaciones. En El sujeto y el poder, Foucault (1982) explica cómo el sujeto ha sido objeto de varios tipos de objetivaciones, para mostrar los modos en los que los seres humanos se transforman a sí mismos en sujetos en dos planos de actuación: "[...] sujeto a otro por control

3 En las relaciones de poder/resistencia, algunas imágenes de identidad son utilizadas para negociar o recomponer valoraciones estereotipadas de sí mismo. Un trabajo interesante en esta línea es el de Mona (2007) que muestra cómo la imagen de identidad es utilizada por las mujeres, políticas camboyanas, como una estrategia de resistencia que parte del reconocimiento de pertenencia a un grupo marginalizado, para movilizar mayores niveles de participación. y dependencia y sujeto como constreñido a su propia identidad, a la conciencia y a su propio autoconocimiento. Ambos significados sugieren una forma de poder que sojuzga y constituye al sujeto" (p. 5). Los dos últimos libros de Foucault sobre la sexualidad, El uso de los placeres (1986a) y La inquietud de sí (1986b) destacan el problema de qué entender por el sujeto en distintas sociedades, que él llama diagramas de poder, ya sea, por ejemplo, en el diagrama griego, cristiano, monárquico, en la disciplina o en el diagrama de la actual sociedad de control.

En los diagramas de poder, el maestro, sus organizaciones, sus luchas, su resistencia activa (acción) o pasiva (no acción) conforman un punto de apoyo, revés, ancla, mina de otros poderes que buscan gobernarlo. Como sujeto público al docente se le exigen muchas tareas y de él se esperan muchos comportamientos. De las sociedades disciplinarias a las sociedades de control se han sucedido una serie de prácticas que lo han hecho objeto de múltiples grillas de observación, evaluación y control. Unas del orden de lo técnico (formatos, fichas, exámenes); otras del orden de la sutileza referidas por ejemplo al cumplimiento de su misión, el reto de formar a los niños y jóvenes del mañana, el desafío de mantener al día su desarrollo profesional o del orden jurídico referidas a las funciones y obligaciones que los maestros tienen que cumplir para validar su perfil y competencias. Es decir, variados y múltiples mecanismos de poder/resistencia se advierten en estas relaciones donde el maestro también ejerce poder, resiste, se organiza y define su subjetividad, se afirma como sujeto de saber o rechaza, por ejemplo, la denominación de instructor para luchar por defender unas condiciones particulares de existencia.

Desde esta perspectiva, Touraine (2000) explica que el sujeto no significa reflexión sobre sí mismo ni sobre la experiencia vivida. En un mundo donde el ser humano está transformado en objeto, el sujeto se opone a los que se ha intentado Ilamar primero papeles sociales, es decir 
a la "construcción de la vida social y personal por obra de los centros de poder que crean consumidores, electores y un público, al menos en la medida en que ofrecen respuestas a demandas sociales y culturales" (p. 231). Por eso, aclara que el sujeto no es de ninguna manera un individuo encerrado en sí mismo, incapaz de intervenir en su situación social, es decir no es simplemente un individuo pasivo que consume normas e instituciones sino también productor de esa vida social y sus cambios. Esto explica el poder productivo de la resistencia, lo cual evidencia que las relaciones poder/resistencia son siempre de fuerza contra fuerza. Como corolario de este hilo conductor, la resistencia aquí se entiende como una práctica en la que el maestro lucha por liberarse de conceptualizaciones impuestas y predeterminadas desde el deber ser; en este sentido, la resistencia conduce a procesos de transformación de la propia subjetividad mostrando a su vez las contrariedades que refuerzan el sistema que combaten.

\section{Lucha como campo para rastrear la resistencia}

El reconocimiento de los distintos escenarios en los que el maestro lucha por mejorar sus condiciones de existencia implica adentrarse en el tema del poder y en el análisis del tipo de luchas que organiza. De hecho, cuando se analiza la bibliografía relacionada con la resistencia como categoría (Sábato, 2000, Foucault, 2000; Giroux; 2003; Touraine; 2000) nociones como poder, libertad y lucha emergen y permiten establecer las condiciones de posibilidad de una variedad de relaciones, respuestas, reacciones, resultados entre sujetos, objetos e instituciones. En El sujeto y poder, Foucault (1982) refiere que el poder se ejerce sobre sujetos libres, es decir sobre sujetos con capacidad de conducir acciones en virtud de su propia acción (p. 253), de su posibilidad de resistencia. Lo que quiere decir que "los seres humanos no están totalmente determinados por prácticas de dominación, sino que tienen la libertad de modificar, rechazar o aceptar las reglas o las lógicas que se les quieren imponer" (Giroux, 2003). Desde esta perspectiva, una noción de poder que no toma al derecho, la ley, ni la dominación ${ }^{4}$ como su centro, sino que reconoce la libertad y la posibilidad de actos libres (Sábato, 2000), permite advertir en el antagonismo de estrategias, la resistencia del sujeto que se niega a ser controlado, vigilado, modelado e intervenido por una fuerza que no provenga de sí mismo 5 .

Pero hay varias resistencias que constituyen excepciones, casos especiales: posibles, necesarias, improbables, espontáneas, salvajes, solitarias, concertadas, rastreras, violentas, irreconciliables, rápidas para la transacción, interesadas o sacrificiales; por definición, no pueden existir sino en el campo estratégico de las relaciones de poder. Pero ello no significa que solo sean su contrapartida, la marca en hueco de un vaciado del poder, formando respecto de la esencial dominación un revés finalmente siempre pasivo, destinado a la indefinida derrota. Las resistencias no dependen de algunos principios heterogéneos; mas no por eso son engaño o promesa necesariamente frustrada. Constituyen el otro término en las relaciones de poder; en ellas se inscriben como el irreducible elemento enfrentador. (Foucault, 2005, p.116).

Ahora bien, cuando muchos historiadores hacen referencia a las luchas de los maestros (gremiales,

4 Para Foucault (2000) no hay relaciones de poder que triunfen por completo y cuya dominación sea imposible de eludir, pues estas abren la posibilidad de una resistencia. En sus palabras, las relaciones de poder "no pueden existir más que en función de una multiplicidad de puntos de resistencia: estos desempeñan, en las relaciones de poder, el papel de adversario, de blanco, de apoyo, de saliente para una aprehensión" (p. 57).

5 A pesar de que Giroux y Foucault analizan el problema del poder desde lógicas distintas, ambos coinciden en que la noción de poder no puede ser subsumida bajo la categoría de dominación (Giroux, 2003), pues visto de esta manera, desconoce cómo los mecanismos de dominación son reproducidos (aceptados) o rechazados por el sujeto. Aunque Giroux apela a Foucault para caracterizar al poder como una fuerza productiva y a la vez restrictiva, su mirada inscrita en la lógica dialéctica entra en un plano de consideración distinto a la mirada foucaultina. Para Lazzarato (2007) la lógica dialéctica valora términos contradictorios en un elemento homogéneo que promete resolverlos en una reconciliación, mientras la lógica estratégica tiene la función de establecer posibles conexiones entre términos dispares que siguen siendo dispares. 
reivindicativas, oposición a normas, entre otras), las analizan en una lógica de poder como dominación entre Estado y magisterio inmanente, en la que la resistencia magisterial se mira como simple oposición ligada al contenido de una lucha inmutable (Meler, 2010). Esto da la impresión de que la lucha ha sido siempre contra el Estado y de que no ha sido influenciada por los cambios históricos y por el poder de distintas fuerzas (económicas, sociales, políticas, gremiales, académicas), en la que el maestro mismo y su resistencia, intervienen y resultan afectados y afectando su historia.

El archivo de la resistencia que se construyó en esta investigación, permite cartografiar el carácter de las luchas de los maestros, e identificar distintos tipos y niveles de luchas. Aquí se enfatiza cada una de ellas como una forma que, dependiendo de la fuerza con la que se dota, adquiere un sentido, una orientación, una funcionalidad, produce discursos y sujetos. En este plano de análisis, es necesario advertir cómo el sujeto responde (resiste) a una determinada relación de poder, y señala las prácticas "de resistencia violenta, de huida, de engaño, de estrategias que inviertan la solución" y da paso a una nueva relación de poder (Foucault 1994a, p. 405). Se alude a luchas por mejoras, luchas por: la reivindicación, los derechos, la existencia, la diferencia, luchas de sí, que por su singularidad pueden localizarse en tiempo y espacio, combinarse con otras prácticas y luchas (políticas, económicas, en contra de la sujeción). Se trata de una historia que analiza las prácticas a través de las cuales irrumpen, la superficie en que emergen, se forman y se desarrollan los discursos, las reglas y condiciones que permiten su formación.

Este trabajo, al analizar las luchas de los maestros, no centra solo su atención en la resistencia al poder autoritario (Touraine, 2000) ${ }^{6}$, pues el archivo aquí construido permite advertir que no solo ese tipo de poder convoca resistencia, existen

6 Touraine (2000) considera que "el hombre moderno se ve llevado más directamente que los anteriores a reconocer la idea de sujeto como principio central de resistencia al poder autoritario" (p. 214). Sin negar su existencia, este trabajo desborda esa orientación. otros poderes locales, transitorios, móviles que atraviesan la vida, las instituciones y los aparatos. Por ejemplo, cuando un maestro enfrenta situaciones que lo obligan a tomar decisiones que afectan su persona, trabajo, familia, vida, relaciones amorosas, etc., aunque está sujeto a una serie de constreñimientos, tiene opciones para decidir un curso de acción que no está exento de juicios sobre saber, deber ser, lo que puede aceptarse o rechazarse y que en definitiva será determinante para replegarse o afirmarse, es decir, él también interviene como una fuerza activa o pasiva (no acción), afectando el curso de su historia.

En esta vía, reflexionar sobre lo que se necesita afirmar o rechazar de su propia historia abre camino a "un proceso de lucha por condiciones que le darán a ese individuo oportunidades para tener una existencia autodirigida" (Giroux, 2003, p. 62). No obstante, este proceso no puede limitarse a un problema de llegada o de búsqueda de la redención; pues la idea de sujeto no escapa de esas mismas relaciones de fuerza que se pretenden combatir. Esta doble dimensión del sujeto, alude a la teoría foucaultiana (1982) que explica los modos por los cuales los seres humanos son constituidos en sujetos, ya sea por la acción que ejercen otros sobre estos (prácticas de sujeción) o se constituyen a sí mismos en sujetos por autoconocimiento (prácticas de liberación), es decir por prácticas meditadas y voluntarias mediante las cuales "los hombres no solo se fijan reglas de conducta, sino que procuran transformarse a sí mismos, modificarse en su ser singular y hacer de su vida una obra" (ver Foucault, 1994b). Para Foucault estas prácticas están atravesadas por relaciones de poder que implican esencialmente a la libertad $y$, consecuentemente, estrategias de lucha.

\section{METODOLOGÍA}

Esta investigación utilizó algunas categorías del análisis histórico propuesto por la genealogía y la arqueología (Foucault, 1969), en la línea de trabajo del grupo de Historia de las Prácticas 
Pedagógicas en Colombia (Zuluaga, 1998; Martínez, 1990, 2010) al entender que estas herramientas constituyen una utilería conceptual para la comprensión de unas prácticas específicas. La mirada al pasado para comprender el presente permite entender los modos en que la forma maestro ha sido intervenida por distintas fuerzas, entre ellas, la reforma educativa estatal, el discurso de los organismos internacionales, el discurso sindical, el saber experto, para analizar cómo los maestros reaccionan ante ellas, estableciendo unas formas de organización y lucha que ameritan ser analizadas. Por tanto, los conceptos de eventualización, líneas de fuerza, condiciones de posibilidad, desmultiplicación causal, polimorfismo creciente y puntos en suspenso, son las categorías teóricas y procedimentales que permiten la construcción de un nuevo recurso metodológico: el poliedro de inteligibilidad (Martínez, 2010). Este recurso permite que el objeto sea abordado desde distintos puntos de mira, lo cual posibilita el ingreso de nuevos elementos, al tiempo que permite reconocer en él distintos planos, velocidades y ritmos. Consiste en la construcción de un objeto volumétrico en el que las líneas de fuerzas y las condiciones de posibilidad entrecruzados construyen un número indeterminado pero siempre creciente de caras que actúan como múltiples puntos de vista de la complejidad del fenómeno.

La eventualización sirvió para advertir algo singular y entender lo discontinuo de estos procesos y su contingencia, así como lo estratégico de su emergencia. Eventualizar consiste entonces en mirar de otra manera la historia de las prácticas de resistencia de los maestros (lo decible y lo visible para Deuleze, 2003) a través de sus organizaciones y luchas por mejorar sus condiciones y reclamar un estatuto de profesionalización. Se trató entonces, de intentar identificar cómo los maestros se piensan a sí mismos sujetos de una práctica, a la vez que se interrogan las prácticas de su regulación mediante discursos legislativos y especializados, con el ánimo de hallar algo singular en las prácticas de constitución de sujeto maestro desde los años 1930 en Colombia (fecha en la que irrumpe la preocupación por la formación profesional del maestro y las primeras organizaciones para defender sus derechos) y así tratar de comprender las luchas magisteriales actuales, sus triunfos y derrotas. Se trata de poner en suspenso una serie de premisas que se han tenido sobre el poder y las prácticas de resistencia a partir de un dominio nuevo para el análisis: el funcionamiento de las relaciones de poder y los modos de configuración del sujeto maestro en su apuesta de resistencia (Foucault, 1982).

La investigación ha descrito los discursos como prácticas materializadas en discursos concretos (político, pedagógico, gremial, social). En estos, se reconocen las líneas de fuerza como vectores de poder que reconfiguran prácticas e instituciones, y las condiciones de posibilidad, que permiten analizar las situaciones que desencadenan la emergencia de un determinado acontecimiento; son herramientas metodológicas clave en el conjunto de precauciones propias de cómo se procede en la arqueología. Como hipótesis de trabajo puede decirse que el proceso de sindicalización por la lucha de un estatuto de profesionalización de la docencia se constituyó como la única forma posible de alcanzar derechos políticos, sociales y laborales. Prácticas de poder/saber/resistencia vincularon estos problemas, los resignificaron; así construyeron nuevos discursos y nuevas prácticas en todos los órdenes de la sociedad que agotaron la sindicalización, mas no la anularon. En efecto, como vector de análisis, este estudio se centra en las circunstancias históricas que rodearon las luchas de los maestros, en especial por el logro de un estatuto de profesionalización de la docencia. Sin embargo, no se dejan de lado las relaciones contingentes que determinan y ubican un dispositivo discursivo, unas prácticas reguladas y entrecruzadas en una compleja red que compromete poderes, instituciones, sujetos y discursos. En esta complejidad se intenta analizar cómo los maestros asumen la docencia, qué estatuto le confieren, cómo reaccionaban ante 
las reformas y qué luchas emprendieron, con el propósito de hacer visibles las relaciones de poder/resistencia que contribuyeron a su situación actual, lo que obligó la reclamación, por ejemplo, de la unificación del estatuto docente.

Para analizar las luchas y las prácticas de resistencia de los maestros fue necesaria una desmultiplicación causal 7 , que para Foucault (1994a) trata de un análisis de los acontecimientos según los procesos múltiples que los constituyen. En este caso particular, se plantea que los procesos de constitución de sujeto maestro en las prácticas de resistencia pueden ser descompuestos en una multiplicidad de aristas que quitaron todo el peso causal a factores como las luchas contra el Estado y la norma que históricamente han predominado en el corpus explicativo, para dar cuenta de la resistencia magisterial. Esto evidenciaría luchas más horizontales que verticales, es decir prácticas de resistencia no solo contra el Estado sino también en las relaciones de los maestros consigo mismo, la sociedad y la escuela.

A tal fin la investigación construyó un archivo de tipo arqueológico sobre las prácticas de resistencia de los maestros, para advertir los enunciados y sus transformaciones. El archivo es el que determina que los enunciados no se acumulen en una multitud amorfa o se inscriban simplemente en una linealidad sin ruptura. A través de él se definen reglas y límites que advierten un dominio discursivo, la conservación de enunciados, su validez o invalidez. En otras palabras, este hace posible recoger discursos efectivamente pronunciados y señalar sus transformaciones. En consecuencia, el archivo de este trabajo se ha constituido de diversos documentos sobre los maestros, sus luchas, resistencias, oposiciones, formas de organización, movilización, gobierno,

7 La desmultiplicación causal del objeto a estudiar genera un creciente polimorfismo del objeto de estudio: por ejemplo, polimorfismo de los elementos que se ponen en relación: sujeto, discurso, subjetividad, etc.; polimorfismo de las relaciones descritas: fuerzas, resistencias, incitaciones, posibilitamientos, frenos, dinamizaciones, etc. formación, educación y pedagogía, que se entrecruzan para hacer aparecer lo visible y lo decible en el periodo 1930-2013. Se consideraron diferentes tipos de documentos (informes, boletines, circulares, comunicados, revistas, folletos, periódicos, testimonios en páginas web, blogs, demandas, planes, leyes, decretos, libros, novelas autobiográficas, etc.) que fueron distribuidos en campos documentales y clasificados a partirde su aparente regularidad temática.

Entre estas unidades de análisis y fuentes documentales se destacan las publicaciones de maestros $^{8}$ en revistas especializadas, publicaciones electrónicas en blogs, redes sociales, correos, que sirvieron para rastrear la voz del magisterio, sus reclamaciones, inconformismo y malestar, sus propuestas, contradicciones, su forma de concebir la educación y su quehacer como profesión.

También se revisó la prensa sindical magisterial $^{9}$. En estos materiales se rescataron boletines, comunicados, cartas, informes, folletos, circulares e historias particulares de algunos sindicatos y organizaciones de maestros y, en especial, de la Federación Nacional de Educadores, con el fin de mostrar los reclamos de los maestros en términos de derechos y exigencias al gobierno y a sus propias organizaciones, pero también de advertir la influencia de otras líneas de fuerza provenientes de discursos del comunismo, de la revolución social, del populismo educativo, de la liberación nacional y finalmente su interés por la participación política.

Otra pieza importante del archivo corresponde a los documentos legislativos y oficiales ${ }^{10}$, que constituyen los instrumentos por los cuales

8 La Revista Educación (1930-1940), Revista Alma Nacional (1933 1936), Revista Educación y Cultura (1982-2010), Revista Idearium (1937), Revista Nodos y Nudos (1980-1990), novelas, libros, investigaciones entre otras.

9 Periódicos como el Educador Colombiano (1977-2010), El Esfuerzo (Huila 1930-1934), La Luz (Tolima, 1934-1936). Acción Escolar (1930), Tribuna Magisterial (2012).

10 Las Memorias de Ministro (1930-2010), leyes y decretos, principalmente los Estatutos de Profesionalización Docente de los años 1979 y 2002, y sentencias. 
se formaliza la relación Estado/maestro. Estos son la primera superficie a la que se acude para someter al sujeto maestro controlarlo y determinarlo, asignándole unas condiciones, características y funciones específicas.

También, constituyen este archivo, las publicaciones de saber experto, en su mayoría de organismos internacionales ${ }^{11}$ y nacionales ${ }^{12}$ que han referido el tema de la profesión docente en América, diagnosticándola, sugiriendo reformas, señalando caminos y exigencias. Por último, no puede faltar en este archivo de la resistencia magisterial, la prensa nacional ${ }^{13}$, que trata aspectos como reforma/ cambio, maestro/estudiante, maestro/escuela, maestro/calidad de la educación, maestro/atraso escolar, entre otros; los cuales afectan las formas que tiene la sociedad colombiana de ver y pensar al maestro.
Para finalizar, se identificaron formaciones discursivas como efecto de la tematización y de los tres tipos de lectura realizados: relacional, estratégica y crítica (Zuluaga, 1998) lo que condujo a romper la aparente unidad del documento, texto u obra (Foucault, 1969) y a leer la dispersión de saberes sometidos (Foucault, 2008) que precisan prácticas concretas en las que el funcionamiento de las relaciones de poder/resistencia devela el sujeto que se constituye en ellas. En definitiva, el análisis de este archivo reveló cortes analíticos para construir un poliedro de inteligibilidad en el que se destaca la resistencia que los maestros en su lucha imprimen a la pregunta "¿Quién soy?", y al cambio en la dirección de las mismas.

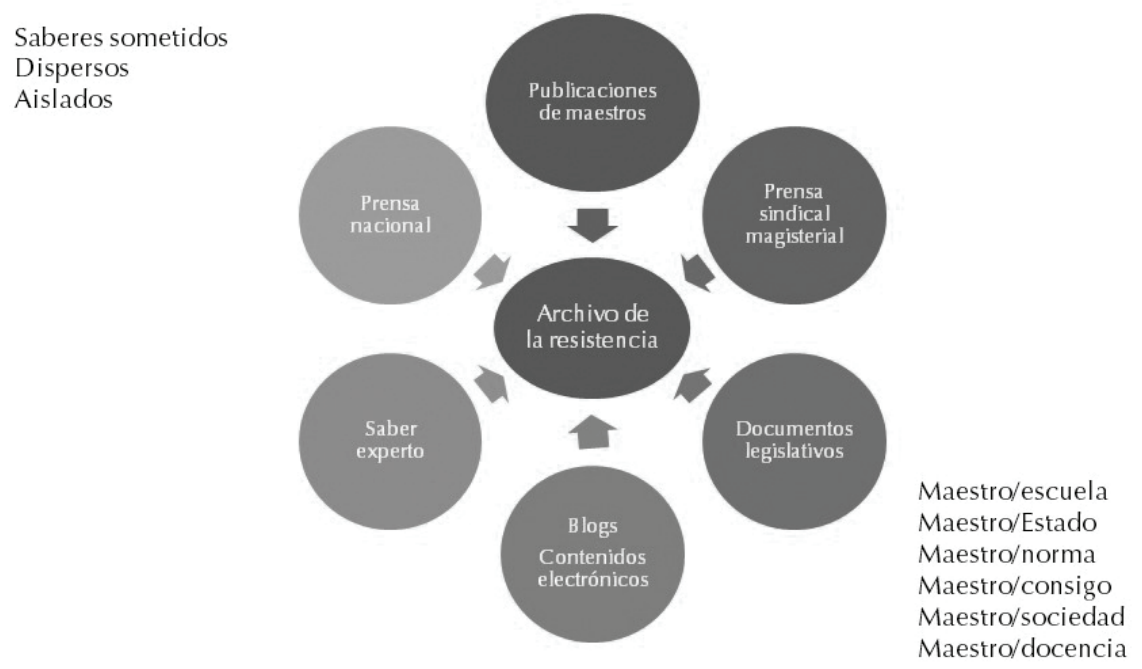

Figura 1. Construcción del archivo de la resistencia.

Fuente: elaboración propia.

11 La Organización de los Estados Americanos (OEA), Organización de las Naciones Unidas para la Educación, la Ciencia y la Cultura (Unesco), Programa de Promoción de la Reforma Educativa (PREAL), Banco Mundial (BM), Fondo Monetario Internacional (FMI).

12 Fundación Compartir, Instituto para la Investigación Educativa y el Desarrollo Pedagógico (IDEP), entre otras.

13 Particularmente los discursos publicados en periódicos como El Tiempo, El Espectador, El Colombiano y La República. 


\section{ANÁLISIS Y DISCUSIÓN DE LOS RESULTADOS}

El archivo permitió identificar tres trayectos importantes (o en palabras de Foucault, puntos de emergencia) de las prácticas de resistencia de los maestros. Un primer trayecto de las prácticas de resistencia (1930-1970), ligado a la lucha gremial reivindicativa, en la que los maestros defendieron su derecho de asociación y sindicalización, reclamaron una mejor preparación y remuneración, la mejora en las condiciones de trabajo y posibilidades de ascenso en el escalafón. En este trayecto, la imagen del maestro virtuoso y apóstol que la sociedad y el Estado legitimaban, condenaba al maestro a la resignada aceptación de su inestabilidad en el cargo, a la baja remuneración en incluso a recibir su salario en especies. Mientras que a la vez se le exigía mejor preparación, decoro y pulcritud al vestir.

El paso siguiente opera de la imagen del maestro virtuoso a la del maestro sindicalizado, a través de una serie de prácticas como las arengas, protestas, acciones de brazos caídos, que afectaron las formas de pensar al maestro y sus luchas. Normas como la promulgación unilateral de los decretos 223/1972 y128/1977 hicieron posibles prácticas como huelgas, marchas y protestas que como causa de la lucha organizada, obligaron la negociación del Decreto 2277 de 1979 entre el Estado y el magisterio. En dicha negociación, los maestros cedieron su aspiración de ser considerados empleados oficiales en sentido estricto, a cambio de un régimen especial de regulación que les otorgaba unas condiciones de ingreso, permanencia y retiro que hacían accesibles para los maestros "unos instrumentos de defensa contra la arbitrariedad y el abuso de las autoridades" (Fecode,1979, p. 1). El Estatuto Docente (Decreto 2277 de 1979)14 fijó las condiciones generales para ejercer la docencia y estipuló que a partir de la fecha "solo podrán ser nombrados para ejercer la docencia en planteles oficiales de educación quienes posean título docente o acrediten estar inscritos en el escalafón nacional docente". De esta manera, se cerraba el paso a los nombramientos considerados ilegales

Tabla 1. Discursos primer trayecto.

\begin{tabular}{|c|c|}
\hline $\begin{array}{l}\text { "El maestro debe ser un sacerdote, un apóstol, su- } \\
\text { ficientemente preparado y bien pagado para que } \\
\text { pueda hacer su labor noble y patriótica" (Marro- } \\
\text { quín, 1943, El Esfuerzo, p.1). }\end{array}$ & $\begin{array}{l}\text { "Si en el estado actual del mundo, se reconoce al albañil y al za- } \\
\text { patero, al bracero y al deshollinador, el derecho de sindicalizar- } \\
\text { se, de constituirse en cuerpo corporativo con los demás colegas } \\
\text { de su oficio para defender sus intereses gremiales y trabajar por } \\
\text { su propio perfeccionamiento, ¿por qué ha de sorprender que } \\
\text { el instructor [...] se vincule también para formar una colectivi- } \\
\text { dad?" (Bernal, 1934, p. 324). }\end{array}$ \\
\hline $\begin{array}{l}\text { "Al maestro, le hemos pedido ante todo pulcritud, } \\
\text { en su vida, en su persona, en el ambiente de su } \\
\text { escuela y de su hogar" (Nieto, 1935). }\end{array}$ & $\begin{array}{l}\text { "En los precisos momentos en que presencia el país el más gran- } \\
\text { de movimiento que registra su historia a favor de los intereses } \\
\text { de los empleados, como este despertar, que por tardío nada des- } \\
\text { merece, de quienes buscan de la unión una fuerza social de que } \\
\text { siempre han carecido para defender sus derechos, los derechos } \\
\text { del gremio más sufrido y olvidado de cuantos pertenecen a la } \\
\text { clase media" (Rev. Idearium, 1937, p. 282). }\end{array}$ \\
\hline $\begin{array}{l}\text { "El maestro debe ser un apóstol que quiere y sabe } \\
\text { ser modelo de virtud, patriotismo y de abnegación } \\
\text { heroica" (Medrano, L. 1949. En MEN p. 48). }\end{array}$ & $\begin{array}{l}\text { "El estímulo para nosotros no existe. Solidarizándonos, impon- } \\
\text { dremos nuestros propios valores, cerraremos las puertas a los } \\
\text { que sorpresivamente pretendan apoderarse de los que nos per- } \\
\text { tenece por títulos de preparación y labor" (ACPES, 1943, p. 1). }\end{array}$ \\
\hline
\end{tabular}

Fuente: elaboración propia. 
por el magisterio (art. 7), y se ligaba la docencia a la especificidad de la formación y la experiencia en el cargo.

En 1980 se identifica el inicio de un segundo trayecto de las prácticas de resistencia en la que se registra el siguiente giro: de luchas verticales a luchas más horizontales. Esto ocurre como consecuencia de la organización del Movimiento Pedagógico Colombiano que emerge como suplemento acontecimental (Badiou, 2003) para reclamar el derecho a orientar su trabajo, así como otras formas de organización y trabajo (redes, expedición pedagógica, anillos) en torno a la pedagogía. La creación de estas nuevas formas de organización: redes, anillos y movimientos, evidencia la búsqueda de la unión para ejercitar formas de resistencia distintas a las de trinchera de la sindicalización. Las relaciones pretendidas buscan eliminar la linealidad de relaciones verticales por relaciones más complejas en curvas, círculos, tejidos. El carácter que se imprime a la resistencia desde dichas organizaciones no solo pone a circular el saber sino relaciones de poder que validan o invalidan saberes, prácticas, sujetos.

El análisis permite identificar cómo el Movimiento Pedagógico Colombiano instaura una forma de lucha diferente que irrumpe como acontecimiento en las luchas reivindicativas que habían caracterizado la acción colectiva magisterial desde la década de 1930, imprimiéndole un nuevo carácter al magisterio que comienza a pensarse como un actor propositivo en torno a su quehacer y a recuperar su identidad como trabajador de la cultura ${ }^{15}$. Sin embargo, conviene precisar que este discurso no estuvo exento de señalamientos que advertían con recelo que este nuevo énfasis e interés por la investigación pedagógica no podía desarticularse de las luchas reivindicativas del magisterio:

15 Habría que preguntarse cómo tales discursos sobre la docencia como profesión, la investigación, los trabajos académicos, los movimientos sociales, etc., configuraron la necesidad de una búsqueda, que el Movimiento Pedagógico asume como rescate.
El movimiento pedagógico como corriente de pensamiento que busca recuperar el rol cultural del maestro en un horizonte liberador no se arriesgará con romanticismos pedagógicos. Sus perspectivas son a largo plazo [...].No se trata pues de que en aras de la pedagogía el educador olvide su carácter de asalariado y de ciudadano y descuide las luchas que como tal debe seguir librando. (Martínez y Rojas, 1984, pp. 5).

En los orígenes del Movimiento Pedagógico se confrontaron dos corrientes contradictorias: por un lado, el movimiento político que subordinaba la pedagogía a lucha magisterial, y, por otro, el de los investigadores ${ }^{16}$ que reclamaban la recuperación de la pedagogía como alternativa para redimir el papel del maestro en la sociedad (Gantiva, 1984, p. 13). Para los primeros, la pedagogía era un instrumento del cual echar mano para abanderar sus consignas, mientras para los segundos, era el medio y la potencia productiva.

Esto pone de manifiesto la existencia de una resistencia instalada en la definición de la identidad del maestro como trabajador de la cultura y poseedor de un saber, animando luchas más horizontales en el seno del movimiento magisterial que actuaron como una fuerza que reclamaba el derecho a la orientación de su trabajo, la autonomía y el reconocimiento de sí mismo como un sujeto de saber, que no se contenta simplemente con reivindicar mejores condiciones de trabajo y empleo, sino que rechaza formas de sujeción impuestas que lo obligan por ejemplo a ser administrador de un currículo diseñado por otros que le dice qué enseñar y cómo enseñar. El archivo revela que la resistencia a las reformas de la época (Reforma Curricular y Mapa Educativo, MEN,19801986) adquiere mayor fuerza y actividad en torno a luchas más afirmativas que de oposición, luchas que reclaman el derecho del maestro a orientar su propio trabajo.

16 Entre estos se destacan: "El proyecto de investigación (interuniversitario) acerca de la historia de la práctica pedagógica colombiana"; el Grupo de Investigación Educativa, dirigido por Carlo Federici; la Expedición Pedagógica de Caldas. 


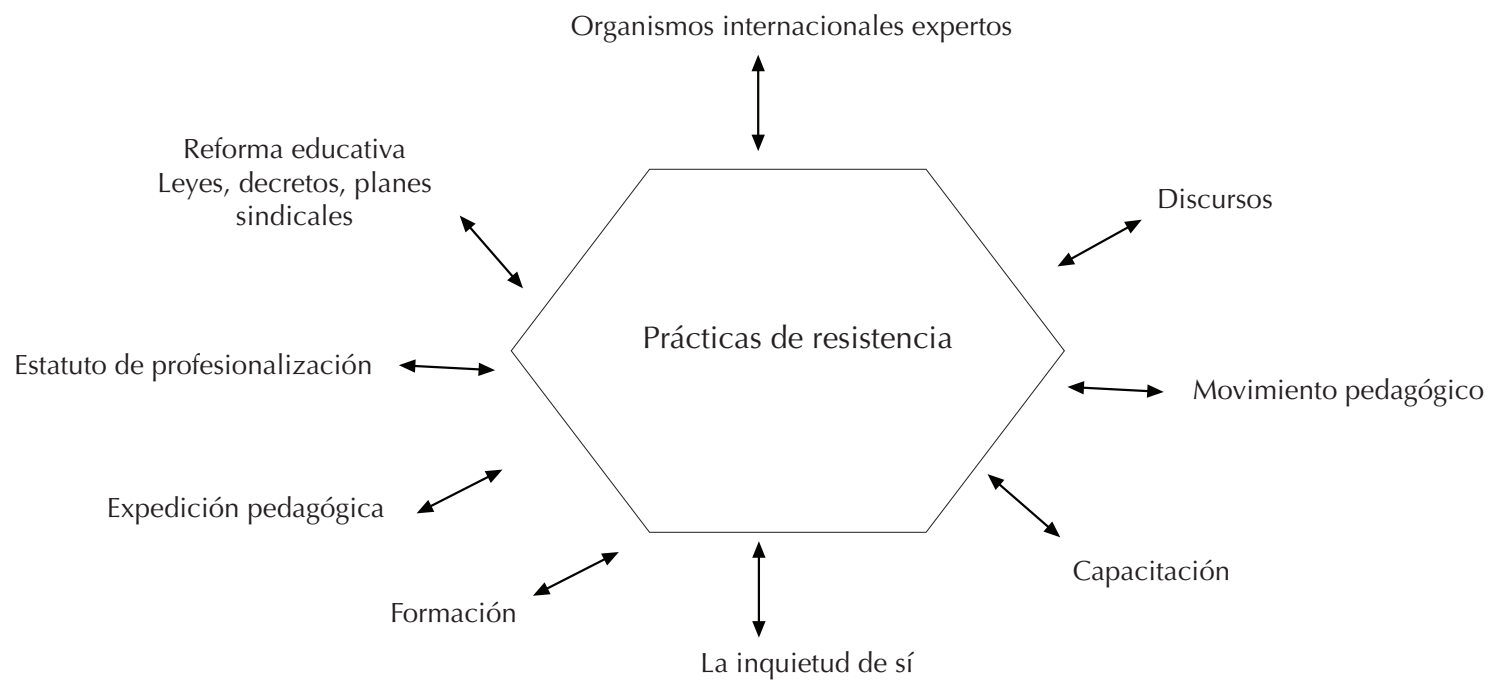

Figura 2. Poliedro, segundo trayecto de las prácticas de resistencia.

Fuente: elaboración propia.

A partir del año 2000 se identifica un tercer trayecto en las luchas de los maestros, cuya característica es el inconformismo y el malestar de los maestros por la intervención de la reforma sancionada en el Nuevo Estatuto Docente (Decreto 1278 de 2002) y la lucha por legitimar al maestro como sujeto de saber y trabajador de la cultura expresada en la defensa de la pedagogía como saber fundante de la profesión docente. Los discursos de los maestros de esta época denuncian la despedagogización y desprofesionalización de la docencia, al tiempo combaten los efectos de esa norma (v.g. la división del gremio en antiguos y nuevos maestros, las pérdidas de un régimen a otro de vinculación, la evaluación de sus competencias y desempeño, etc.).

Frente a la organización magisterial, de nuevo se apela a la unión, la validación de un Proyecto Educativo Pedagógico Alternativo (PEPA), la redención del estatuto del maestro y la elevación social, económica y laboral de la docencia. Las prácticas discursivas de los maestros rechazan la definición de la docencia como función docente, pues con ella se crean unas condiciones de profesionalización de la docencia que habilitan a otros profesionales para su ejercicio, se asimilan y redistribuyen saberes, prácticas y tareas que han sido reclamadas como propias de un campo profesional con formación y titulación específica (la pedagogía).

En este escenario, algunos colectivos de maestros continúan con las luchas reivindicativas (pues aún los maestros son los profesionales peor remunerados), mientras otros, menos reconocidos, lo hacen desde la academia, la investigación y el aula, en luchas más afirmativas. Un conjunto de prácticas y estrategias muestran que hoy son otras las condiciones, discursos y evidencias en las que el maestro debe encontrar formas de resistir el embate de las fuerzas que lo han intervenido (v.g. los discursos que lo responsabilizan del fracaso escolar, la validación social de las TIC, el Nuevo Estatuto Docente (Decreto 1278 de 2002), los bajos resultados de aprendizaje en pruebas estandarizadas). 
Varios estudios arrojan pistas importantes para pensar cómo se han transformado el trabajo y la identidad del maestro. Por ejemplo, los que se han ocupado de la práctica pedagógica y su identidad: Zuluaga (1988), que plantea una distinción entre los sujetos de la enseñanza, maestro y docente para precisar la relación del primero con el método y del segundo con el saber que transmite y la norma; Martínez (2010), cuyo trabajo refiere la dilución del maestro y su despersonificación en la función docente. También los que se han ocupado de la relación docencia/reforma y sus efectos al señalar por ejemplo, la internalización de su rol de funcionario del Estado, la cosificación de la profesión de enseñar, la frustración docente (Díaz, 2010), la desautorización de los docentes (Vezub, 2005).

Por su parte los que han trabajado la relación docencia/sociedad han puesto en evidencia las exigencias y sobrecarga de responsabilidades de los docentes (Esteve, 2006), el desprestigio social de la docencia (Vaillant, 2005), entre muchos otros que también refieren distintos fenómenos a raíz de su malestar, su lugar en la encrucijada (Tiramonti, 2005), su insatisfacción (Braslavsky et al., 1994), sus sentimientos de culpabilidad (Hargreaves, 2005). Es decir, unos discursos de resistencia que advierten que algo anda mal en la forma en la que se piensa la pedagogía, la educación y al maestro. La aparente sinonimia con la que se abordan enunciados distintos (maestro y docente) despoja el discurso de resistencia de los maestros de su contenido constituyente que lo liga a una práctica y a unas maneras de ser y pensarse a sí mismo.

\section{A MANERA DE COLOFÓN}

Al revisar las prácticas de resistencia de los maestros deseamos recuperar tres sentidos. El primero hace visible las múltiples e inesperadas formas de la resistencia que funcionan en la cotidianidad y, especialmente, cuando se insertan en un campo estratégico de luchas, por ejemplo: el dominio de un campo de saber, la mejora de unas condiciones, el establecimiento de unas orientaciones jurídicas sobre otras, etc. El segundo trae a la superficie la comprensión de cómo el discurso es un espacio de lucha por el poder en el que las estrategias planteadas retoman el discurso establecido por otros, para apoyarse y proponer en giros en la manera de ver y pensar el maestro, su lucha y su inconformidad. Por ejemplo, en las luchas por la organización magisterial, observamos cómo los discursos en pro de la unión y la militancia sindical se apoyaron en los discursos de la clase media y sus dificultades para legitimar la sindicalización como práctica. También en las luchas por el primer estatuto de la profesión, se observó cómo el discurso en torno a las profesiones en general decantó un escenario para pensar la norma alrededor de este esquema, que posteriormente fue aprovechado por el discurso oficial para insertar la profesionalización y la función docente. Tercero, el giro hacia luchas más afirmativas de los maestros, que podrían leerse en el nivel de la resistencia y no de la llana oposición, permite advertir la resistencia como una fuerza productiva que negocia con el poder/saber pero también lo fortalece. Por ejemplo, la distinción entre oposición y resistencia mediada por la inquietud de sí, implicó en un momento determinado de las luchas de los maestros, una conciencia crítica frente a cómo resistir la reforma y cómo organizar la lucha. De Movimiento Pedagógico a la consolidación de expresiones distintas del mismo en otras formas de organización (redes, anillos, círculos, expedición), emerge la resistencia a la institucionalización y la búsqueda de formas de establecerse y afirmarse en relación con sus pares, los intelectuales, la investigación. No obstante, no puede dejar de anotarse cómo en la actualidad las redes se han desarrollado bajos dos direcciones: una dirección en la que hay un desplazamiento de la estructura organizativa centrada, y la otra, cuando la idea de red es adoptada y utilizada por el centro y se vuelve una exigencia discriminadora y excluyente. 
Cuando se pregunta por las prácticas de resistencia de los maestros y del maestro que se constituye en ellas, no puede dejar de notarse cómo los maestros responden a relaciones de poder, orientadas por discursos y prácticas, arraigadas incluso en la urdimbre de las más sutiles relaciones sociales. El archivo de esta investigación permitió identificar, analizar y describir formas de enunciar al maestro en los planes de gobierno, leyes, normas, discurso sindical, experto, prensa que circulan emplazándose, superponiéndose, excluyéndose, alternándose, confundiéndose (apóstol, modelo de virtud, héroe, maestro, trabajador de la cultura, docente) que revelan maneras de ver y hacer ver a los maestros de forma diferente dependiendo del régimen de verdad que se establece en una época en el estratégico campo de luchas y pequeños ardides que dan lugar a la intervención de su subjetividad, emplazando la forma sujeto en maestro o docente. En definitiva, si algo puede concluirse en este trabajo es que ¡las prácticas de resistencia son también una forma de poder!,que funcionan en prácticas cotidianas, organizadas, estratégicas para luchar en contra de formas de sujeción impuestas que desconocen las formas de autogobierno como prácticas de libertad (Foucault, 1984).

\section{RECONOCIMIENTOS}

Este proyecto fue auspiciado por la Universidad Santo Tomás de Aquino, en el marco del Doctorado en Educación; Línea "Política, ciudadanía, Educación y derechos humanos". Fue dirigido por el Dr. Alberto Martínez Boom. Se inscribe en la línea de trabajo del grupo Historia de las Prácticas Pedagógicas en Colombia, que retoma la propuesta foucaultiana, específicamente la arqueología que funciona como caja de herramientas, enmarcada en la reflexión histórica, política y filosófica para cuestionar las relaciones sujeto/maestro/poder/resistencia.

\section{REFERENCIAS}

ACPES (1943). Circular No. 1 de 1943. Archivo (mimeo).

Badiou, A. (2003). El ser y el acontecimiento. Buenos Aires: Manantial.

Bernal, R. (1934). Editorial. Revista Educación, Órgano de la Facultad de Educación de la Universidad Nacional, 2(11), 324-325.

Braslavsky et al. (1994). Las características de la profesión maestro y la calidad de la educación en América Latina. Proyecto Principal de Educación en América Latina y el Caribe. Boletín 34. Santiago de Chile: Unesco. Recuperado de: http://unesdoc. unesco.org/images/0010/001002/100200s.pdf

Ceid-Feco de (julio de 1984). Movimiento Pedagógico. Otra escuela, otros maestros. Revista Educación y Cultura, 1(1), 4-12.

Deleuze, G. (2003). Foucault. Barcelona: Paidós.

Díaz, A. (2010). Tarea docente. Una perspectiva didáctica grupal y psicosocial. México: Ed. Nueva Imagen, Universidad Nacional Autónoma de México.

Esteve, J. (2006). Identidad y desafíos de la condición docente. En: El oficio de docente: vocación, trabajo y profesión en el siglo XXI (pp. 19-45). Buenos Aires: Unesco, IIPE, Fundación OSDE y Siglo XXI Editores.

Fecode (1979). Acta Acuerdos y Desacuerdos. En: Estatuto Docente (Decreto 2277 de 1979). Colombia.

Fornet-Betancourt, R.; Becker, H. y Gómez-Muller, A. (1984). Michel Foucault. La ética del cuidado de uno mismo como práctica de la libertad. Entrevista con Michel Foucault. Revista Concordia, 6, 96-116.

Foucault, M. (1969). Arqueología del saber. Buenos Aires: Siglo XXI Editores.

Foucault, M. (1982). El sujeto y el poder. Revista Mexicana de Sociología, 50(3), 3-20.

Foucault. M. (1986a). Historia de la sexualidad 2: El uso de los placeres. Madrid: Siglo XXI.

Foucault. M. (1986b). Historia de la sexualidad 3: La inquietud de sí. Madrid: Siglo XXI.

Foucault (1994a). Ditsetécrits IV. París: Gallimard.

Foucault (1994b). Ditsetécrits I. París: Gallimard. 
Foucault, M. (2000). Un diálogo sobre el poder y otras conversaciones. Madrid: Alianza Editorial.

Foucault (2005). Historia de la sexualidad 1: la voluntad de saber. México: Siglo XXI Editores.

Foucault, M. (2007). El nacimiento de la biopolítica. Buenos Aires: Fondo de Cultura Económica.

Foucault (2008). Defender la sociedad. Buenos Aires: Fondo de Cultura Económica.

Gantiva, J. (1984). Orígenes del Movimiento Pedagógico. Revista Educación y Cultura, 1(1), 13-17

Giroux, H. (2003). Teoría y resistencia en educación. México: Siglo XXI Editores.

Hargreaves, A. (2005). Profesorado, cultura y postmodernidad: cambian los tiempos, cambia el profesorado. Trad. P. Manzano. 5a. ed. Madrid: Ediciones Morata.

Lazzarato, M. (2007). Biopolítica y control de la opinión pública. En: La filosofía de la diferencia y el pensamiento menor (pp. 105-134). Bogotá, D. C.: Universidad Central, lesco.

Martínez, A. y Rojas, F. (1.984). Movimiento Pedagógico. Revista Educación y Cultura, 1(1), 4-12.

Marroquín, S. (20 de julio de 1934). Editorial. Voceros de las inquietudes del magisterio del Huila. El Esfuerzo, p. 1-2.Neiva.

Martínez B., A. (1990). Una mirada arqueológica a la pedagogía. Bogotá: Universidad Pedagógica Nacional.

Martínez B., A. (2010). La dilución del maestro. Palabra Maestra, 25, p. 5. Bogotá: Fundación Compartir. Recuperado de: http://www.palabramaestra.org/ admin/docs/1291299843Palabra\%20Maestra\%20 25\%20Final\%20sin\%20editorial.pdf

Medrano, L. (1949). Informe del Departamento Normalista. En MEN. Memoria del Ministro de Educación Nacional, Dr. Arango, Eliseo. República de Colombia.

Meler, E. (2010). Perplejidades acerca de la conciencia desventurada. Buenos Aires: Del Signo.

Mona, L. (2007). Speakings'of resistances. Women politicians negotiating discursive power in Cambodia. Gutemburgo: Göteborg University.

Nieto, A. (1935). La Educación Nacional. Informe rendido al MEN. Revista Educación, 1(3), 24-25.
Presidencia de la República de Colombia. Decreto 223 de 1972.

Presidencia de la República de Colombia. Decreto 128 del 20 de enero de 1977. Por el cual se dicta el estatuto del personal docente de enseñanza primaria y secundaria a cargo de la Nación.

Presidencia de la República de Colombia. Decreto 2277 de 1979. Por el cual se adoptan normas sobre el ejercicio de la profesión docente.

Presidencia de la República de Colombia. Decreto 1278 de 2002. Por el cual se expide el Estatuto de Profesionalización Docente.

Revista Idearium (diciembre de 1937). Órgano de la Escuela Normal de Occidente. 1(7).

Sábato, E. (2000). La resistencia. Buenos Aires: Editorial Planeta Argentina, Seix Barral.

Street, S. (1997). Veinte años de la escuela democrática en el magisterio mexicano. Revista Viento del Sur, 1(10), 32-37.

Street, S. (1998a). El sindicalismo docente en México ¿Fuerza institucional o sujeto social? FLACSO/ PREAL, Boletín No. 2. Buenos Aires: Proyecto Sindicalismo docente y reforma educativa en América Latina.

Street, S. (1998b). El movimiento magisterial como sujeto democrático ¿Autonomización de los educadores o ciudanización de la educación? El Cotidiano, 1(87), 7-15. UAM.

Tiramonti, G. (2001). Sindicalismo docente y reforma educativa en la América Latina de los 90.PREAL, No. 19, Buenos Aires.

Tenti F., E. (2005). La condición docente. Análisis comparado de la Argentina, Brasil, Perú y Uruguay. Buenos Aires: Siglo XXI Editores.

Tenti F., E. (2006). El oficio de docente. Vocación, trabajo y profesión en el siglo XXI. Buenos Aires: Siglo XXI.

Tiramonti, G. (2005). La escuela en la encrucijada del cambio epocal. Educação \& Sociedade, 26(92), 889-910. Recuperado de: http://www. scielo.br/scielo.php?script=sci_arttext\&pi$\mathrm{d}=$ S0101-73302005000300009\&lng=en\&tln$\mathrm{g}=\mathrm{es} .10 .1590 / \mathrm{S} 0101-73302005000300009$. 
Touraine, A. (2000). Crítica de la modernidad. Bogotá: Fondo de Cultura Económica.

Vaillant, D. (2005). Formación de Docentes en América Latina. Re-inventando el modelo tradicional. Barcelona: Octaedro.

Vezub, L. (2005). El discurso de la capacitación docente. Una aproximación a las políticas de perfeccionamiento en la Provincia de Buenos $\mathrm{Ai}$ res. Espacios en Blanco, Revista de Educación, 15, 211-242.

Zuluaga, O. (1998).Pedagogía e historia. La historicidad de la pedagogía. La enseñanza, un objeto de saber. Medellín: Editorial Universidad de Antioquia, Anthropos, Siglo del Hombre Editores. 